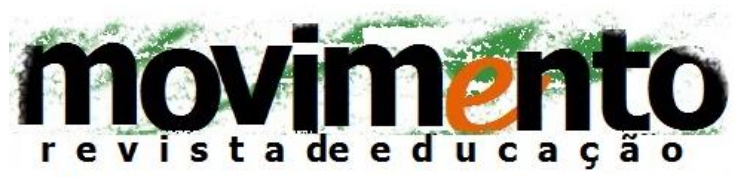 \\ faculdade de educação - programa de pós-graduação em educação \\ universidade federal fluminense \\ issn 2359-3296 \\ ano 3 número 4 - 2016
}

\section{MODOS DE SER JOVEM NA ESCOLA: um estudo de caso etnográfico}

\author{
Livian Lino Netto ${ }^{1}$ \\ Cristhianny Bento Barreiro²
}

\section{RESUMO}

O artigo apresenta um recorte de pesquisa realizada com estudantes do Instituto Federal Sul-rio-grandense, que teve por objetivo descrever imagens da juventude com foco na percepção que os jovens têm sobre si mesmos na escola. A partir de princípios qualitativos, o estudo caracterizou-se como estudo de caso de inspiração etnográfica. A coleta foi realizada através da filmagem de documentários pelos estudantes sobre o que é ser jovem na escola e qual o sentido da mesma em suas vidas. Como resultado, afirma-se que o principal sentido atribuído pelos jovens à escola é o estar junto com o outro.

Palavras-chave: Juventudes, Escola, Contemporaneidade.

\section{ABSTRACT}

This paper presents a research conducted with students of the Federal Institute of South of RS, which aimed to describe the images of youth, focusing on the description of the perceptions that young people have about themselves and about school. The research, based on qualitative principles, may be characterized as a case study of ethnographic inspiration. The samples were collected through the filming of documentaries by students about what is to be young at school and what its meaning. As result, it is stated that the main meaning given by young people to school is being together with the other.

Keywords: Youth, School, Contemporary.

\footnotetext{
1 Mestre em Educação. Professora formadora do Programa Pró-Funcionário do IFSUL. livianlino@gmail.com

2 Doutora em Educação. Professora do Programa de Pós-graduação em Educação do IFSUL. crisbbarreiro@gmail.com
} 


\section{INTRODUÇÃO}

Este artigo apresenta um recorte da pesquisa realizada com 120 jovens do Instituto Federal de Educação, Ciência e Tecnologia Sul-rio-grandense - campus Pelotas - IFSUL, que teve por objetivo descrever imagens da juventude contemporânea. Por imagens, entendem-se as aparências, as representações, os gostos e os estilos de vida dos jovens pesquisados, que se transformam nas projeções em produto cultural socialmente construído, passando a representar a juventude de maneira geral. Porém, descrever imagens trata-se de uma tarefa difícil, principalmente quando são muitas as imagens e representações ${ }^{3}$ de juventude construídas nas pesquisas que tratam do tema como categoria de análise, considerando, cada uma delas, as particularidades, tais como o espaço geográfico em que foram realizadas as pesquisas citadas, as condições sociais e culturais e os contextos históricos em que estes autores produziram suas pesquisas (DAYRELL, 2003, 2007, 2009; CARMO, 2000; SPOSITO, 1997, 2008).

As pesquisas relacionadas à juventude ou aos jovens descrevem diversas características dessa fase como sendo de conflito, de rebeldia, de transição, de transformação do que se é para o que se pretende ser.

Estudos como os de Dayrell (2007) e de Sposito (1997) sobre jovens são realizados no interior da escola, espaço em que a juventude pode ser percebida na produção de sentidos sobre o mundo. A escola também pode ser responsável pela criação da noção de juventude, da mesma forma que a juventude reinventa a escola como lugar de sociabilidade juvenil (PEREIRA, 2007).

A partir do momento em que começa a fazer parte da escola, o indivíduo participa de uma instituição com regras definidas, em que há uma grande convivência com

\footnotetext{
${ }^{3}$ Para Jodelet (2001), trata-se de um sistema de interpretação que rege nossa relação com o mundo e com os outros.
} 
muitas diferenças. A escola é, assim, importante espaço no processo de socialização e de produção das identidades e das culturas juvenis. Porém, ao mesmo tempo, parece muito distante dos interesses destes jovens. Nesse tempo em que as mudanças são muito rápidas e constantes, a escola parece permanecer intacta e sólida em meio à fluidez das vivências que abriga.

Segundo Dayrell (2007, p.1106),

[...] para os jovens, a escola mostra distante dos seus interesses, reduzida a um cotidiano enfadonho, com professores que pouco acrescentam à sua formação, tornando-se cada vez mais uma "obrigação" necessária, tendo em vista a necessidade dos diplomas. Parece que assistimos a uma crise da escola na sua relação com a juventude, com professores e jovens se perguntando a que ela se propõe.

No entanto, apesar de parecer muitas vezes parada no tempo, a escola se constitui num importante espaço de convivência e de produção social da juventude. No interior dessa instituição, pode-se observar diversas formas de viver e de perceber o mundo. Sendo assim, esta pesquisa se realiza dentro do espaço escolar, já que talvez, a partir dele, possa-se compreender as maneiras de se produzir enquanto jovem e, assim, criar imagens da juventude.

Mas segundo Dayrell (2007, p.1115),

[...] assistimos ao desmoronamento dos muros que garantiam uma autonomia das instituições, tornando difícil distinguir o dentro e o fora, com os contornos cada vez mais tênues. É a mídia que penetra e interfere em todos os espaços institucionais; é a família que se mostra cada vez mais permeável às influências do consumo e seus apelos.

A escola vem sendo permeada por acontecimentos que antes ficavam do lado de fora, que não ultrapassavam os muros dessa instituição. Hoje, há a influência de fatores "exteriores" a essa instituição que acabam por fazer parte da formação dos jovens, dos professores e de todos que convivem nesse espaço. 
A partir da década de 1990, com expansão do ensino público, as escolas passam a receber uma quantidade muito grande de estudantes, oriundos de diferentes contextos sociais e que trazem consigo experiências de desigualdade, preconceito, pobreza e exclusão, o que de certa maneira, acaba trazendo para o interior da escola a reprodução de uma estrutura social, muitas vezes excludente, com conflitos e contradições vistas na sociedade colocando novos desafios que necessitam ser superados pela escola e pela educação.

Este trabalho descreve, a partir da visão dos jovens do IFSul, imagens de ser jovem na escola que podem contribuir para pensar possibilidades para os desafios do tempo contemporâneo. A seguir, descreve-se o percurso trilhado pela investigação para buscar atender a este objetivo.

\section{Os caminhos desta pesquisa}

Com o objetivo de descrever imagens de juventude produzidas pelos próprios jovens, esta pesquisa iniciou seu trajeto, tendo como questão: Quais imagens sobre os modos de ser jovem são produzidas pelos estudantes do IFSul? Para dar conta dessa descrição, foi necessário pensar quem seriam os jovens selecionados e como seriam capturadas as imagens de suas realidades e os modos de ser jovem por eles narrados.

Visto que, como professora da disciplina de Sociologia no Instituto, eu tinha contato com jovens que estavam cursando o Ensino Médio Integrado, a escolha dos sujeitos não foi uma tarefa difícil, já que das sete turmas com as quais eu trabalhava no primeiro semestre de 2013, três eram do curso de Ensino de Jovens e Adultos e as outras quatro de Ensino Médio, cujos estudantes frequentavam essa etapa de ensino em idade regular. Dessa forma, os adolescentes escolhidos faziam parte das turmas dos cursos técnicos em Eletrônica, Comunicação Visual e Química e tinham idade entre 14 a 18 anos. Sendo assim, esses foram os sujeitos jovens, segundo a faixa etária que se utiliza para definir juventude, a serem pesquisados. (SPOSITO; CARRANO, 2003). 
O Curso Técnico Integrado de Comunicação Visual é um curso relativamente novo, e seu currículo já havia sido alterado para atender a Lei 11.684 (BRASIL, 2008), que inclui as disciplinas de Sociologia e Filosofia como disciplinas obrigatórias nos três anos de Ensino Médio. Então, esse curso possui na sua grade curricular 4 semestres com a disciplina de Sociologia e $4 \mathrm{com}$ a de Filosofia. Os vinte e quatro estudantes deste curso estavam tendo seu primeiro contato com a disciplina de Sociologia, e estavam cursando o segundo semestre. Já no curso Técnico Integrado em Química, os estudantes estavam cursando o que seria equivalente ao terceiro ano do ensino médio, então a faixa etária dessa turma era maior do que a dos demais, regulando entre 16 e 18 anos. A turma tinha dezessete estudantes. Neste curso, a disciplina de Sociologia, bem como a de Filosofia, estavam presentes em apenas um semestre do curso, de um total de oito, por duas horas-aula semanais, sendo necessário cumprir dez diferentes unidades temáticas que compunham o conteúdo da disciplina.

Duas outras turmas eram do Curso Técnico Integrado de Eletrônica, e os estudantes estavam cursando a disciplina de Sociologia II. Essas duas turmas se caracterizavam pela quantidade de estudantes, sendo a turma da manhã composta por 42 e a turma da tarde por 39 .

Nas duas primeiras semanas de aula do primeiro semestre de 2013, eu na condição de professora da disciplina, expliquei o que seria o conteúdo de Sociologia em cada uma das turmas. No Curso de Eletrônica, o primeiro conteúdo a ser trabalhado na disciplina era Cultura, o que facilitou o desenvolvimento das atividades ao longo do semestre. Já nas outras duas turmas, o primeiro conteúdo a ser trabalhado era Sociologia Clássica, com autores tais como: Marx, Weber e Durkheim. Assim, era necessário pensar propostas que pudessem dar oportunidade dos jovens se descreverem, se expressarem. 
Cinco atividades foram pensadas para que, a partir de temas do cotidiano da juventude, como a relação com a família, amigos e escola, bem como com a tecnologia, a música, a religião, a sexualidade e o consumo, fosse possibilitada a construção um texto com inspiração etnográfica que descrevesse a cultura desses jovens. A escolha desses temas como eixos para a elaboração dos instrumentos de coleta teve como subsídio o que as pesquisas e publicações relacionadas aos jovens relatam. (SPOSITO, 1993, 1997, 2008; DAYRELL, 2001, 2003, 2007, 2009, VELHO, 2006; ABRAMO, 1997; PAIS, 2006).

Como atividades, propôs-se a gravação de um $C D$ com as músicas que o estudante gostava de escutar, uma colagem em que a temática fosse o que o jovem consome e o que gostaria de consumir, caso seu poder aquisitivo the permitisse, a escrita de um diário de final de semana com a narrativa de tudo o que fez, pensou e sentiu ao longo desses dois dias, uma fotografia em conjunto com um texto em que relatasse suas atividades em casa e, por fim, um documentário em que expressasse sua relação com o espaço escolar.

A realização das atividades durou cerca de quatro meses, durante o ano de 2013.

Neste artigo, apresenta-se como recorte a análise dos documentários produzidos, única atividade que poderia ser realizada em grupo, cujo foco deveria relacionar-se ao tempo passado pelos jovens na escola. Como o grupo vê a escola? foi a grande questão norteadora do instrumento. Para isso, os estudantes precisaram se organizar em grupos de afinidades, escolhidos por eles e com no máximo 6 componentes, para criar um roteiro que mostrasse a sua percepção do ambiente escolar, já que é o lugar em que eles passam boa parte tempo. A partir do roteiro, cada grupo gravou um documentário que retratou a maneira como o grupo via a escola e se percebia dentro dela.

A gravação dos documentários movimentou os grupos e as quatro turmas envolvidas esforçaram-se para, em no mínimo 5 minutos e no máximo 15 , 
mostrar como era estar na escola e como eles se percebiam nesse ambiente. A resistência do início se transformou em compartilhamentos em redes sociais 4 . Era preciso tentar construir uma teoria que emergisse da descrição densa da cultura juvenil, nesse contexto, nesse tempo, que abrangesse interpretações dos dados coletados, porém não pela visão de um adulto, mas aproximando-se das interpretações do que os próprios jovens descreveram.

Esta investigação teve como base os pressupostos da pesquisa qualitativa que, segundo Angrosino (2009), visa a identificar o mundo lá fora e entender, descrever e, às vezes, explicar fenômenos sociais de dentro, de diversas maneiras diferentes. Ao definir a juventude como tema desta pesquisa, o caminho metodológico para a descrição precisava de um olhar sensível que não partisse da referência da adultez, mas sim do olhar do próprio jovem sobre si. Dessa forma, realizar um estudo de caso de inspiração etnográfica foi a opção metodológica utilizada na busca dessa descrição. Sendo assim, esta pesquisa caracteriza-se como uma investigação qualitativa, com inspiração antropológica etnográfica que estuda a cultura e a sociedade.

Pesquisou-se os jovens na escola, a fim de tentar descrever e interpretar suas possibilidades de ser, buscando construir imagens que sejam descritas a partir do que eles pensam, dizem e produzem, com uma sensibilidade que possibilitasse pensar não apenas concretamente a juventude, mas sim, criativamente com eles. A seguir, passa-se a descrição de como veem a escola, a partir dos documentários produzidos.

\section{Estudantes: como veem e produzem imagens de uma escola}

\footnotetext{
${ }^{4}$ Os estudantes compartilharam seus vídeos no You Tube, site que permite que seus usuários carreguem e compartilhem vídeos em formato digital, e no Facebook, que permite compartilhar vídeos entre os Amigos.
} 
Para apreender o que estes jovens pensavam e sentiam sobre a escola, foi proposta uma atividade de criação de documentários com o objetivo de gravar o que enxergavam no seu dia a dia dentro desse espaço. Com a proposta de realizar um vídeo curto, de no mínimo cinco minutos e no máximo quinze, os estudantes organizarem-se em grupos a fim de pensar em um roteiro. Esta atividade os envolveu bastante, fazendo com que passassem a frequentar a escola, durante alguns dias, nos turnos inversos as suas aulas. Além de realizar as gravações, eles precisaram elaborar um roteiro, o que atribuiu um caráter reflexivo a atividade, e se preocupar com a edição e composição das imagens. Logo foi possível perceber que os estudantes estavam muito envolvidos com a realização do documentário, procurando materiais para realizar as gravações, como câmeras e celulares, além de selecionarem cenas, aulas e espaços que eles consideravam que representasse seu dia a dia dentro do Instituto. Alguns professores e funcionários contribuíram para que pudessem realizar as gravações, emprestando materiais e deixando com que eles utilizassem salas de aula que não estavam sendo usadas. Muitos utilizaram espaços das aulas de outras disciplinas para gravar seu dia a dia dentro da escola.

Ao final, dezesseis documentários foram entregues. Nas datas previstas para a entrega, os estudantes assistiram aos documentários produzidos com os colegas, e alguns dos vídeos foram compartilhados no You Tube e no Facebook, a partir do desejo expresso pelos autores.

Pode-se perceber que alguns vídeos acabaram por fugir um pouco da proposta de responder a pergunta sobre o que a escola significava para eles ou como se percebiam na escola, já que professores, e funcionários foram entrevistados para dar o seu ponto de vista sobre o Instituto. Ainda assim, a partir da edição dos vídeos, é possível perceber, de certa forma implícita, os sentimentos dos jovens dentro da escola.

Por exemplo, em dois vídeos, o trajeto da casa dos estudantes até a chegada ao campus foi feito acompanhado de trilhas sonoras tristes, como se fosse um 
sacrifício ir até a escola para ter aula. Ou então, o que chama a atenção em um dos documentários é a letra da música escolhida, HighwaytoHell, para ilustrar o caminho que a estudante percorre toda a manhã para chegar até a escola. Então, essa sensação de estar caminhando na estrada para o inferno, parece estar presente para além dos documentários, em outros trabalhos ou falas dos estudantes.

Ao assistir os documentários, pode-se perceber que uma importante função atribuída para a escola é a de espaço de socialização. Assim, lugares como os jardins e a cantina aparecem como centrais, pontos de encontro para momentos em que não estão em sala de aula.

Fica claro, na fala dos estudantes que aparecem nos vídeos, que estar na escola parece ser mais importante pelas relações, amizades e motivos outros que não seja estar em aula.

Eles reclamam dos professores e das disciplinas "matéria chata, conteúdo chato, professor chato, prova chata" o que evidencia que o estar na escola é estar junto com outros colegas em outras atividades. Alguns trabalhos de pesquisa reafirmam a percepção de que o estar na escola, para os estudantes, é muito mais interessante do ponto de vista de estar com os outros, seus colegas, ocupando os jardins e salas de aula vazias do que estar na sala de aula, o que contribui para a informação de que o tempo que eles perdem fora de aula, na escola, é recuperado em casa, estudando. (DAYRELL, 2003, 2007; BARBOSA, 2007).

Dos dezesseis documentários, quatro foram publicados pelos estudantes no You Tube. Esses vídeos servirão, neste trabalho, de referência para os demais, já que, de certa forma, demonstram o que os demais também relatam. Assim, a partir desse momento, será realizada a descrição dos mesmos. 


\section{Documentário um: o cenário de entrevistas}

Este documentário apresenta os estudantes entrevistando dois professores, um funcionário e um colega de aula. Cada trecho do documentário foi gravado em diferentes locais da escola. O funcionário foi entrevistado no lugar em que exerce sua função, o corredor, já que monitora os estudantes durante o período das aulas. O professor de disciplinas técnicas foi entrevistado dentro de um dos laboratórios específicos utilizado nas disciplinas práticas. O outro professor, de história, foi entrevistado em um dos jardins da instituição. O aluno, que também fazia parte do grupo, opinou sobre a escola, tendo como cenário também um dos jardins da instituição.

O servidor, perguntado sobre o que a escola representa para ele, respondeu que a escola era como se fosse sua segunda casa, já que passa muito tempo dentro da instituição, e que percebe os estudantes como seus filhos, pois ao trabalhar na inspetoria tem contato direto e intenso com os mesmos, resolvendo problemas momentâneos. O funcionário relata ainda que exerce esta função há 20 anos.

O segundo entrevistado, professor de disciplinas específicas, relata que faz parte desta escola há pelo menos 20 anos, já que é egresso da mesma e que retorna como professor contratado. Ele relata ter recordações boas da escola e que está gostando da experiência de ser professor, já que pode participar, acompanhar e, principalmente, aprender com os estudantes e demais colegas professores. $O$ outro professor é perguntado sobre o que pensa a respeito da escola e dos estudantes. Ele responde que faz parte da escola há pouco tempo, porém ressalta que a escola é boa por possuir uma estrutura que lhe permite desenvolver um bom trabalho. Destaca que os estudantes nesta escola são bons, inteligentes e curiosos, diferentes dos demais com os quais trabalha em outras escolas. Os dois professores entrevistados são contratados e trabalham 
na escola há pouco tempo, o primeiro, há cerca de um ano e, o outro, há apenas três meses.

Pode-se perceber que os estudantes escolheram como cenários os locais que gostam de frequentar, os jardins, o corredor, local em que todos se encontram, e os laboratórios do curso, lugar em que realizam aulas práticas.

As entrevistas com os professores e funcionário, apesar de não ser o foco da proposta, ainda assim parecem mostrar as percepções sobre a escola, já que o critério de escolha dos professores foi a afinidade, não apenas pessoal, mas com os conhecimentos. Percebe-se que um dos professores carregava a característica de ensinar uma disciplina com uma grande carga prática, e o outro, professor de história, disciplina com a qual os estudantes parecem ter mais proximidade.

A última entrevista apresentada no vídeo foi com o colega de grupo que parece relatar a visão de seus integrantes acerca do que pensam sobre a escola. $O$ estudante afirma que a escola é boa para poder se conviver com pessoas diferentes. Relata a importância da escola, já que se trata de uma escola de reconhecida qualidade de ensino. Ressalta ainda que as práticas esportivas são também um ponto bastante importante deste ambiente. Conclui, reafirmando que, de fato, o mais importante é conviver com todas as pessoas que fazem parte da escola, relatando que cada pessoa significa uma vivência diferente e que é essa diferença que faz a instituição ser tão grande e que o convívio com essas diferenças faz com que eles se sintam normais.

\section{Documentário dois: Highway to Hell}

O segundo documentário narra o primeiro contato dos alunos com a instituição, a verificação de seu nome na lista de aprovados do curso, em que os 
componentes do grupo aparecem sublinhados para que sejam identificados, e em seguida, aparecem sorrindo, um a um, mostrando que ficaram felizes por ter entrado para esta escola.

Logo, uma das componentes do grupo vai mostrando o trajeto que percorre da saída de sua casa até a chegada à escola. Percebe-se que esse caminho começa a ser feito à noite e, conforme ela vai se aproximando da escola, o dia vai clareando até que, enfim, ela chega pela manhã no colégio.

Durante o caminho, a estudante vai mostrando as coisas e lugares pelos quais passa todos os dias, bem como o tempo que gasta para realizar o deslocamento. Este caminho é mostrado no vídeo ao som de uma música cujo título traduzido é "estrada para o inferno". As imagens parecem expressar diversos sentimentos sobre o ir para a escola. Imagens de caminhos tristes e de corredores tristes foram recorrentes na maioria dos vídeos entregues pelos alunos.

Na sequência, o grupo mostra como convivem e interagem com os colegas, durante o tempo que ficam na escola e pode-se notar que talvez o convívio com os colegas seja o elemento de destaque deste documentário, já que depois de a menina terminar seu caminho até chegar à sala de aula, as imagens mostram o tempo em que eles permanecem em sala sem estar estudando. Nesse momento, uma das estudantes, ao ser perguntada sobre o que pensa sobre a escola, responde dizendo: "tirando ter que estudar, é bom". Assim, a escola parece ser mais importante para o convívio com os outros do que para estudar. De certa maneira, o vídeo também reafirma o que o anterior mostrou, a importância atribuída aos professores na instituição. Apesar de demonstrarem algum desapreço por ser necessário estudar, pode-se perceber que os alunos reconhecem que seus professores são importantes devido à sua qualificação e formação, reconhecendo que essas características fazem diferença na sua própria formação. 
O vídeo prossegue mostrando salas de aula sem professores, jogos de carta, brincadeiras entre os colegas. Ainda assim, nesses espaços vagos, sem aula, eles realizam atividades que parecem lhes dar prazer discutindo questões relacionadas aos estudos. Por exemplo, durante o jogo de cartas filmado, os estudantes discutem a resolução das questões relativas à prova de matemática.

O vídeo vai mostrando os lugares nos quais os alunos parecem mais gostar de estar, o que inclui a cantina, como um espaço de convivência entre pessoas de diferentes cursos. Além das salas de aula e da cantina, o vídeo mostra as aulas em si e apresenta a preocupação dos estudantes alunos em ser aprovados. Nesse vídeo e nos demais, as disciplinas das ciências exatas são retratadas como não tão boas, mas como as mais importantes ou, talvez, como aquelas que oferecem maior risco de reprovação.

Na sequência, o documentário mostra as aulas de português, matemática, e física, e, nesta última, é retratado o dia em que a turma recebeu as notas de uma das últimas avaliações do semestre.

O final do vídeo demonstra um contraste em relação ao início do mesmo, já que os integrantes do grupo aparecem tristes e cabisbaixos, finalizando a produção.

\section{Documentário três: um curso que habita o corredor}

O terceiro documentário público começa com os estudantes caminhando em um dos corredores da escola e um convite do grupo para que se conheça o Instituto. Assim que se inicia a visita, uma trilha sonora que parece triste começa a tocar. A entrada sempre aparece como um momento triste e a música segue até a chegada aos corredores do curso, lugar em que os estudantes costumam permanecer para realizar as atividades. Logo após, o grupo apresenta o curso ao qual fazem parte, mostrando os corredores, explicando o que cada objeto 
significa para eles. Como se trata de um curso de comunicação visual, o corredor é composto por inúmeros elementos que parecem contribuir para construção de sua identidade. $O$ corredor é composto por vários elementos visuais, pinturas nas portas e mesas de desenho nas quais os estudantes desse curso passam algum tempo realizando atividades.

Além dos corredores, a educação física e os esportes aparecem novamente como um componente importante no dia a dia deles na escola. $\mathrm{O}$ documentário também não mostra com entrevistas a opinião ou a percepção que os componentes têm da escola, porém os elementos visuais e as músicas, bem como as legendas colocadas para ilustrar o que pensam e sentem, reforça a ideia dos demais: a escola é lugar de convívio com os colegas no qual o estudo não é o mais importante para eles. Logo depois de apresentarem os lugares do curso, o documentário apresenta suas ideias, sintetizada na frase: "Assim é nossa vida no IF, entre alegrias e exatas".

As imagens, em preto e branco, representam a maior parte do vídeo, também parecem traduzir certa tristeza pelo estar na escola. E, por outro lado, as alegrias mostradas estão presentes nas brincadeiras com os colegas e nos tempos em que dividem os espaços de lazer dentro da escola. O vídeo encerra com mais um momento em que os estudantes aparecem reunidos do lado de fora de uma aula.

\section{Documentário quatro: relações entre a escola e a casa}

O último documentário é o mais extenso deles e reforça as ideias já trazidas pelos outros documentários, tantos nos descritos aqui, como nos demais trabalhos entregues: escola é um lugar do estar junto. 
O documentário mostra diferentes lugares que, apesar de não pertencerem à escola, também são incorporados a ela como lugar de convívio, mostrando que as relações feitas por eles na escola se estendem a outros lugares de convivência. O vídeo inicia com cenas da casa dos estudantes antes de irem para e escola. Mesmo que o vídeo também não mostre com depoimentos as percepções que os alunos têm sobre o estar na escola, as imagens parecem reforçar o que já apareceu nos demais documentários. Assim, os estudantes do grupo mostram imagens de diferentes lugares aos quais frequentam: as salas de aula, os jardins e as suas próprias casas, cenários utilizados na descrição dos modos de estar na escola.

Até chegar à escola para ter aulas, os estudantes dividem seus tempos nas casas dos colegas, entre brincadeiras e estudos. Os principais territórios que aparecem neste documentário são a casa, a escola em geral e os jardins da escola. O jardim configura-se como espaço de convívio, em que sentados ao sol, conversam e trocam experiências, e assim parecem aprender. Nas cenas realizadas neste espaço, os estudantes aparecem pensando e discutindo sobre o que falar ou colocar no trabalho. Diferente dos demais vídeos, neste não aparecem aulas ou disciplinas, mas diversos discursos trazidos para o interior da escola.

O vídeo transita entre os ambientes da casa e da escola e, de certa forma, em como se relacionam: o tempo em casa e na escola, principalmente nos jardins e nas salas de aulas vazias, com os colegas entre brincadeiras e aprendizagens. Neste vídeo, não são mostradas cenas em aula e nem são enfocadas as avaliações, como em outros, mas são trazidos discursos, estereotipados e satirizados, sobre o porquê de frequentar a escola, exemplificados por uma cena, ao final do vídeo, em que um dos integrantes imita um viciado em drogas para relatar que frequenta a escola para se livrar do tráfico.

\section{Percepções sobre a escola: análise sobre as imagens}


De maneira geral, os quatro documentários retratam percepções semelhantes aos demais, que não foram aqui diretamente descritos. Assim, os vídeos publicados servem para exemplificar os demais, a partir de categoria que emerge: a escola enquanto espaço coletivo, de relações e de grupos. O pátio, os corredores, a sala de aula, materializam a convivência rotineira de pessoas (DAYRELL, 2003). Esses espaços configuram-se como ponto de encontro e de socialização, de construção de identidades, de afinidades e de convivência entre os jovens, dos mais diferentes grupos e espaços, neste caso dentro da escola. Para autores como Canclini (2004), Leccardi (2005) e Feixa (2006), os jovens precisam ser estudados e entendidos a partir do mundo em que vivem e não comparados a grupos que viveram em outras décadas ou a certos modelos ou padrões de comportamento tornados hegemônicos (SCHWERTNER; FISCHER, 2012).

Praticamente todos os documentários apresentam ideias semelhantes e a frase "tirando ter que estudar, o resto é bom" aparece como se todos tivessem combinado que tal ideia faria parte dos trabalhos.

De maneira geral, mostram os ambientes dentro da escola nos quais preferem estar com os demais colegas. Os jardins, a cantina, as salas de aula (sem professor), os corredores são os principais cenários dos vídeos que, também, mostram cenas dos jovens em casa, porém realizando atividades relacionadas ao colégio e com seus colegas (de aula ou de escola), relações estabelecidas dentro do ambiente escolar que se estendem para fora do mesmo.

Segundo Dayrell (2007, p.1116-1117),

[...] a escola tende a não reconhecer o "jovem" existente no "aluno", muito menos compreender a diversidade, seja étnica, de gênero ou de orientação sexual, entre outras expressões, com a qual a condição juvenil se apresenta. [...] no caso dos jovens, por exemplo, eles criam momentos próprios de socialização baseada nas 
relações de amizade, nos espaços intersticiais fora e dentro das instituições, inclusive na própria escola, onde trocam informações e produzem aprendizagens.

Dessa forma, dentro e fora da escola, os jovens produzem momentos de socialização, de convivência e de aprendizagens. Os vídeos relatam estes espaços que parecem ter permanecidos engessados no tempo. Assim, para os jovens pesquisados, a escola tem um papel fundamental na sua formação acadêmica, mas principalmente em sua formação humana, como espaço de convivência com colegas, amigos e amores.

A escola é um lugar, como alguns disseram, como se fosse a sua segunda casa, já que passam a maior parte dos seus dias nela, e como diz Dayrell (2003, p.2),

[...] apreender a escola como construção social implica, assim, compreendê-la no seu fazer cotidiano, onde os sujeitos não são apenas agentes passivos diante da estrutura. Ao contrário, trata-se de uma relação em contínua construção, de conflitos e negociações em função de circunstâncias determinadas.

Assim, dar voz aos jovens e as suas percepções sobre a escola, talvez possa contribuir para se pensar esse espaço, no qual se passa um grande tempo de vida.

Os jovens dessa pesquisa revelam suas percepções sobre a escola e como passam os dias, entre a obrigação de estudar e a vontade de estar em outros lugares dentro da escola.

A ideia de que a escola é um espaço fixo, duro e chato, é trazida como contraditória, pois é, ao mesmo tempo, um espaço flexível, relacionado ao convívio, aos amigos e as alegrias: "e assim é a nossa vida no IF, entre alegrias e exatas". Nessa frase é possível perceber a ambiguidade de fazer parte desse espaço. 
De maneira geral, os documentários relatam o dia a dia dos jovens que se dividem entre os amigos, os jardins e a cantina e expressam os significados que atribuem a cada um desses elementos, reafirmando a ideia encontrada em vários dos trabalhos descritos, de que a escola se constitui de um conjunto de tempos e espaços ritualizados. Em cada situação, há uma dimensão simbólica, que se expressa nos gestos e posturas acompanhados de sentimentos. (DAYRELL, 2003).

A vida cotidiana dos jovens tem um conjunto de experiências sociais que são vivenciadas e constituem um determinado modo de ser jovem e que pode influenciar suas participações na escola, que por outro lado apresenta características próprias, não sendo uma realidade homogênea, articulando diferentes dimensões que são ordenadas por um conjunto de regras que buscam delimitar e unificar a ação dos seus sujeitos (DAYRELL, 2003).

As percepções de que a escola é chata, de que se não precisassem estudar era melhor são muito fortes nas descrições que os alunos fazem sobre a escola, apesar de considerarem que os professores são qualificados e que a escola a que pertencem é referência em educação de qualidade.

Em praticamente todos os documentários os pontos apontados como negativos da escola relacionam-se ao acordar cedo, aulas de disciplinas exatas, provas, certos tipos de trabalhos e educação física, em que precisam correr ou fazer circuitos.

Outra coisa que é ruim no IF é que tu tem que te acordar muito cedo pra vir pra cá, tipo, 6 horas, é muito cedo na minha opinião e tem que pegar ônibus e caminhar, ah é muito trabalho, a outra coisa ruim é a educação física, três vezes por semana, pessoal vocês acham isso justo ter $3 \times$ por semana educação física? Pois é... (vídeo 1).

Ou, como afirma o aluno no vídeo 2: 
Tudo que é posto em educação e aprendizagem que é o que deveria ser o alvo do colégio é a parte ruim, eu acredito que o colégio tem muito pra evoluir, eu poderia te dar todos os detalhes porque geralmente eu não saberia explicar, mas ultimamente o colégio está caracterizado pelas atitudes de qualquer jovem no pensamento como uma prisão, é um lugar de desaponto, não é um lugar de aprendizagem e crescimento porque por mais que as pessoas levem as coisas brincando, quando há uma, um certo, uma certa mostra de ideal de interesse por alguma coisa e há um certo, um professor passar e colocar aquilo como uma coisa legal, qualquer pessoa se dispõe a aprender e a conhecer, e não é isso que a gente vemos no colégio, vimos matérias chatas, os professor chatos, lugares chatos, provas chatas, coisas que hoje em dia pra nossa poderia ser bem melhor e é isso.

Segundo o depoimento do vídeo, a escola é vista como uma prisão em que parece que os processos de ensino e de aprendizagem permanecem os mesmos de outros tempos e que estes não são mais interessantes para estes jovens neste contexto contemporâneo de mundo, rápido, fluido, líquido (BAUMAN, 2001). A relação dos alunos, dentro da escola entre os colegas, parece de certa forma acompanhar essa fluidez, mas ao mesmo tempo, os processos de ensino e aprendizagem parecem estar presos às tradições, em que a concepção de aluno remete a uma sociedade moderna. (DAYRELL, 2007).

Conforme Dayrell (2007, p.1119), na escola da sociedade moderna,

[...] quando o jovem adentrava naquele espaço, deixava sua realidade nos seus portões, convertendo-se em aluno, devendo interiorizar uma disciplina escolar e investir em uma aprendizagem de conhecimentos. Em um modelo ideal, muito próximo àquele que regia o mundo do trabalho e o trabalhador, esperava-se que 0 aluno fosse disciplina do obediente, pontual e se envolvesse com os estudos com eficiência e eficácia. Ao mesmo tempo, não se considerava os alunos na sua dimensão de jovens, numa tendência em representar ambos os conceitos como se fossem, de alguma forma, equivalentes. 
De certa maneira, segundo o relato dos estudantes nos documentários, isso ainda parece acontecer na escola. E eles precisam deixar as suas juventudes fora do contexto escolar.

As imagens mostram o caminho pela estrada para o inferno, no sentido de que os estudantes não parecem se sentirem livres, mas presos às condições tradicionais de educação em um contexto ao que não sentem pertencimento. $\mathrm{E}$ mesmo que às vezes algumas práticas tentem romper com esses paradigmas modernos, construídos socialmente, do papel da escola para a formação dos jovens, as mesmas parecem esbarrar em um sistema arraigado e que não permite que se acompanhe o correr do tempo de rapidez, de informação e de impermanências.

Pelos relatos dos estudantes pode-se perceber que a escola segue homogeneizante, fixa e fora da diversidade e da diferença que transita nos seus espaços, em que a diversidade sociocultural dos jovens segue sendo reduzida a diferenças apreendidas no enfoque da cognição (inteligente ou com dificuldades de aprendizagem; esforçado ou preguiçoso) ou no do comportamento (bom ou mau aluno, obediente ou rebelde), conforme Dayrell (2007).

Nesse contexto, ainda segundo Dayrell (2003, p.22),

[...] o professor não diz e os alunos também não perguntam. Parece que a resposta está implícita: o conhecimento é aquele consagrado nos programas e materializado nos livros didáticos. O conhecimento escolar se reduz a um conjunto de informações já construídas, cabendo ao professor transmiti-las e, aos alunos, memorizá-las. São descontextualizadas, sem uma intencionalidade explícita e, muito menos, uma articulação com a realidade dos alunos.

Parece que os estudantes têm essa percepção das aulas e dos conteúdos e da escola, porque assim vem sendo construída. Para poder suportar essa chatice, eles acabam criando outros modos de estar na escola e aproveitar esse tempo, fazendo com que passe mais depressa, de maneira mais agradável, com 
brincadeiras nos jardins, na cantina ou em salas de aula em que não tenha professor, construindo outras experiências de se estar na escola.

Como lembra Dayrell (2007, p.16),

[...] a escola é invadida pela vida juvenil, com seus looks, pelas grifes, pelo comércio de artigos juvenis, constituindo-se como um espaço também para os amores, as amizades, gostos e distinções de todo tipo. O "tornar-se aluno" já não significa tanto a submissão a modelos prévios, ao contrário, consiste em construir sua experiência como tal.

Apesar das mudanças do mundo contemporâneo, segundo Barbosa (2007), a escola ainda parece assumir um papel importante de formação de seres humanos. Entender os sentidos que os jovens atribuem às relações sociais, no seu interior é importante já que outros espaços das vidas dos jovens começam a fazer parte desse ambiente que é cada vez mais invadido por outras formas de ver e de se estar no mundo, seus consumos e suas concepções e percepções da vida social.

Assim, levar em conta o jovem como sujeito implica considerar que no interior da escola existem processos, lugares, situações e, sobretudo, relações que podem contribuir na construção da subjetividade do jovem e de possíveis outras formas de viver os processos educativos.

O estar com os colegas e amigos e não estar estudando são pontos importantes da escola para estes jovens que relatam em sua maioria que, estar na escola é bom por essa convivência.

Bom, eu já tive vários colegas, muitas pessoas nesta instituição. Cada pessoa significa uma vivência diferente, todas as pessoas são diferentes, acho que isso que faz a instituição ser tão grande, pessoas que, com classes sociais distintas, cores, raças, tudo que faz isso ser essa enorme instituição, acho que o viver com essas pessoas é o que é o mais importante, o convívio, é a diferença de classes que faz nós nos sentir tão normais. (vídeo 3). 
Essa experiência de estar com o outro, com pessoas diferentes parece ser uma das principais motivações para os jovens frequentarem a escola. No relato acima, o jovem diz que o que para ele faz a instituição ser grande é o fato de poder dividir esse espaço com pessoas diferentes, de classes sociais diferentes e que faz com que eles possam ter diversas experiências nesse espaço. A escola como instrumento de socialização aparece como uma das principais percepções dos jovens sobre a escola.

Estar na escola, significa estar junto, estar misturado e participar de grupos e de experiências diferentes a cada dia e, conforme Dayrell (2007), a escola aparece como um espaço aberto a uma vida não escolar, de uma comunidade ou uma rede, em que se constituem grupos e trocas subjetivas em um palco de competições, conflitos, amizades e amores. Dentro da escola, nos bancos, jardins e salas de aula é possível perceber esses modos de ser jovem que tentam, de certa forma, modificar as estruturas modernas da escola, em que cada vez mais são colocadas suas maneiras de ver e de pensar o mundo que criam para se sentir parte do ambiente que parece não dar conta de seus anseios e angústias, bem como de suas curiosidades que por estarem fora dos conteúdos das disciplinas, encontram-se cada vez mais nas redes sociais e em outros circuitos de convivência.

O que eu acho do colégio, pra mim o colégio é um lugar de meio social muito bom (...) mais socialmente quando eu falo bem melhor é porque muitas amizades são feitas lá dentro, muitas pessoas se... há muito, muita até intimidade, com outras pessoas, coisas que ultimamente não conseguimos fazer com outras pessoas em outro lugar. (vídeo 1)

Como ambiente de socialização, a escola aparece como um meio social favorável já que, pelo modelo estruturado, faz com que os jovens tenham uma vivencia em tempos estabelecidos. Assim, as percepções da escola como ambiente socializador são filmadas e constantes nos documentários. 
Mas, apesar de estudar parecer ser o menos importante para os jovens, a importância do ensino e da qualificação é ressaltada nos depoimentos, que relatam saber que por fazerem parte de uma instituição federal, eles se sentem privilegiados, se comparados com estudantes de outras escolas ou instituições públicas. A formação dos professores, a estrutura da escola e uma consciência de que fazem parte de uma instituição que por vezes parece não sofrer com poucos recursos é valorizada pelos jovens.

\begin{abstract}
Essa instituição ela tem grande nome, ela é... Ela tem renome nacional, e eu acho que isso é o principal, o importante é a vivencia com as outras pessoas, é bons professores atuando nas áreas onde tentam nos ensinar para nos dar um bom futuro do qual apenas trabalharemos para um sistema falho do qual criaram mais impostos do qual tiraram mais o nosso dinheiro, tiraram mais o nosso tempo, onde pudemos ver belas paisagens fora da instituição, não temos muito, mas aproveita estes 4 anos de estudantes que somos, pra aproveitar essa boa vida que acaba logo depois da formatura, sabemos que tem o nosso trabalho e tudo de ruim na nossa vida. (vídeo 3)
\end{abstract}

Nota-se que o estudante, contrariando o que aparece em alguns estudos que abordam uma perspectiva clássica sobre os jovens, de rebeldia e alienação, percebe que, mesmo tendo um bom ensino, em uma instituição de renome e os professores tentarem ensinar o que é necessário para se ter um bom trabalho, vai entrar em um sistema de exploração, em que essas formas de estar na escola e de ser jovem não serão mais contempladas, pela falta de tempo, que priva as pessoas de outras maneiras de participar da vida e do mundo.

Outra ideia que pode ser percebida é consciência de que não é preciso empenhar um enorme tempo estudando. Apesar de isso não ser consenso entre os estudantes, a percepção de que já existe muito conhecimento pronto e que eles só precisam procurar na internet aparece, já que relatam que para fazer os trabalhos, o Google faz para eles. Essa ideia é reforçada principalmente com trabalhos que são das áreas das Ciências Humanas ou das linguagens, já que em matemática e física isso é quase que impossível, segundo os mesmos. 
Essa noção de que tudo que está posto na internet, nos jornais e no mundo é conhecimento, de certa maneira, parece ter sido construída nas experiências que eles têm com os meios de comunicação. A diferença entre informação e conhecimento não parece estar clara, ao menos na percepção dos jovens que participaram desta pesquisa.

A gente acabou de sair de uma prova de geografia, uma prova muito interessante, tinha que fazer um texto, o Google fez pra gente. (vídeo 1)

De maneira geral, os documentários relatam o cotidiano dos alunos na escola e suas percepções sobre estar nela e. Os vídeos mostram os espaços que os alunos frequentam, além das aulas, os jardins, os bancos, a cantina como espaços importantes de ocupação e socialização dos quais participam, dentro do ambiente escolar.

\section{Considerações sobre juventude e escola}

Vários elementos surgiram como percepções da escola pelos jovens. Dentre estes, merece destaque a ideia de que estudar não é a principal atividade que lá se realiza, mas sim estar com outros, com os colegas. A escola parece estar parada no tempo, não contemplando outras ou novas formas de participar desse tempo que tem características diferenciadas, tais como a rapidez, a fluidez e as mudanças constantes. (BAUMAN, 2001) Tendo em vista que o tempo em que se vive pode ser caracterizado pela rapidez, pela fluidez e pela incerteza, e que os planejamentos ficam cada vez mais difíceis face às inconstâncias desse momento, parece importante pensar sobre como essas características se relacionam com a produção de juventudes na escola. 
Ao iniciar a pesquisa, foi necessário estudar sobre as juventudes. Esse termo, utilizado no plural, remete ao sentido de que, assim como estilos de vida podem ser diversos, apenas uma descrição não pode dar conta das tantas possibilidades de ser jovem. Ao utilizar-se como exemplo os estudos de Dayrell (2003, 2007, 2009), pode-se perceber que os jovens por ele pesquisados, por pertencerem a outros contextos sociais, têm outras percepções da sua juventude, inviabilizando a realização de quaisquer generalizações. Assim, utilizar a palavra no plural parece ser uma forma de tentar incluir todas as possibilidades que possam haver, além de alertar para o risco que uma identidade única ou simplificada pode trazer.

Os jovens ainda parecem ser vistos apenas como estudantes dentro da escola, e não como agentes que participam do mundo e que podem transformá-lo. Os relatos dos jovens e trabalhos como os de Dayrell $(2003 ; 2007)$ mostram que o sistema escolar não contempla as juventudes, já que parece estar engessada no tempo moderno em que a tarefa da escola ainda é a transmissão de conhecimentos e não a construção dos mesmos.

Os relatos de que a escola é chata, as tarefas chatas, os professores chatos, as provas chatas, parecem ser pontos os quais ainda precisam ser pensados nos sistemas de educação, já que os jovens mostram grande interesse em estar com os outros e isso parece não ser aproveitado como momento formativo na construção juvenil contemporânea. Estes relatos contradizem a ideia inicial de que a escola é um lugar de alegria e felicidade, já que a escolha dos cenários, das músicas e as falas dos alunos no decorrer dos trabalhos mostram que essa alegria parece existir apenas nos momentos de convívio com seus colegas e fora da sala de aula. Acontece no espaço escolar, mas parece algo que é desvinculado dele. Discutir juventudes na escola torna-se relevante já que os próprios jovens delatam as falhas que ainda estão presentes no dentro desta instituição. 
Considerar a pluralidade, as culturas e os modos e imagens de ser jovem nesse tempo precisa ser pensado por quem participa dos processos educativos formais instituídos na sociedade, a fim de pensar uma educação e uma escola em que os jovens se sintam potencializados nas suas formas de ser jovens, atentando para as culturas juvenis e para as construções de si nas relações sociais tanto na escola quanto no mundo.

\section{REFERÊNCIAS}

ANGROSINO, Michael. Etnografia e observação participante. Porto Alegre. Editora Artmed, 2009.

ABRAMO, Helena Wendel. Considerações sobre a tematização social da juventude no Brasil. Revista Brasileira de Educação, Rio de Janeiro, n.5 e n.6, p. 25 - 36, maio/dez. 1997.

BARBOSA, Daniele de Souza. Tamo junto e misturado! Estudo sobre a sociabilidade de jovens alunos em uma escola pública. DISSERTAÇÃO (Mestrado em Educação) Faculdade de Educação, Universidade Federal de Minas Gerais, Belo Horizonte, 2007.

BAUMAN, Zygmunt. Modernidade Líquida. Rio de Janeiro: Zahar, 2001.

BRASIL, Lei Federal 11.684 de 02 de junho de 2008. Altera o art. 36 da Lei no 9.394, de 20 de dezembro de 1996, que estabelece as diretrizes e bases da educação nacional, para incluir a Filosofia e a Sociologia como disciplinas obrigatórias nos currículos do ensino médio. Disponível em: http://www.planalto.gov.br/ccivil_03/_Ato2007-2010/2008/Lei/L11684.htm Acesso em: 05 de janeiro de 2014.

CANCLINI, Néstor García. Diferentes, Desiguales y Desconectados: mapas de la intertextualidad. Barcelona: Gedisa, 2004.

DAYRELL, Juarez. A Música entra em cena: O Rap e o Funk na socialização da juventude em Belo Horizonte. TESE (Doutorado em Educação). Faculdade de Educação, Universidade de São Paulo, São Paulo. 2001.

DAYRELL, Juarez. O jovem como sujeito social. Revista Brasileira de Educação, n.24, Set /Out/Nov /Dez 2003.

DAYRELL, Juarez. A escola faz juventudes? Reflexões em torno da socialização juvenil. Educação e Sociedade, Campinas, v.28, n.100 - Especial, p.1105-1128, Out. 2007. 
DAYRELL, Juarez. Juventude e escola. In: SPÓSITO, Marília Pontes. Estado da Arte sobre juventude na pós-graduação brasileira: educação, ciências sociais e serviço social (1999-2006). Belo Horizonte, MG : Argvmentvm, 2009.

FEIXA, Carles. Generación XX - teorías sobre lajuventudenla era contemporánea. Revista Latinoamericana de CienciasSociales, Niñez y Juventud, [S.I.], v. 4, n. 02, p. 3-18, 2006.

LECCARDI, Carmem. Por um novo significado do futuro: mudança social, jovens e tempo. Tempo Social, Revista de Sociologia da USP, São Paulo, v.17, n.2, 2005.

JODELET, Denise. As representações sociais. Rio de janeiro: Editora da UERJ, 2001.

PAIS, José Machado. Buscas de si: expressividades e identidades juvenis. In: ALMEIDA, Maria Isabel Mendes de; EUGENIO, Fernanda. (ORG.) Culturas Jovens: novos mapas do afeto. Rio de janeiro: Zahar, 2006.

PEREIRA, Alexandre Barbosa. Aprendendo a ser jovem: A escola como espaço de sociabilidade juvenil. In: XIII Congresso Brasileiro de Sociologia, 2007. Recife, Anais do XIII Congresso Brasileiro de Sociologia, 2007.

SCHWERTNER, Suzana Feldens; FISCHER, Rosa Maria Bueno. Juventudes, conectividades múltiplas e novas temporalidades. Educação em Revista, v.28, n.1, p.395-420, 2012.

SPOSITO, Marília. A sociabilidade juvenil e a rua: novos conflitos e ação coletiva na cidade. Tempo Social, Revista de Sociologia da USP, São Paulo, v. 5, n.1 e 2, p.161-178, 1993.

SPOSITO, Marília Pontes. Estudos sobre juventude em educação. Revista Brasileira de Educação, n.5 e 6, p.37-52, mai./jun./jul./set./out./nov./dez. 1997.

SPOSITO, Marilia Pontes. O Estado da Arte sobre juventude na Pósgraduação Brasileira: Educação, Ciências Sociais e Serviço Social (19992006). Belo Horizonte: Argvmentvm, 2008.

SPOSITO, Marília Pontes; CARRANO, Paulo César. Juventude e políticas públicas no Brasil. Revista Brasileira de Educação, n.5 e 6, p.16-39, mai./jun./jul./set./out./nov./dez. 2003.

VELHO, Gilberto. Juventudes, projetos e trajetórias na sociedade. In: ALMEIDA, Maria Isabel Mendes de; EUGENIO, Fernanda. (ORG.) Culturas Jovens: novos mapas do afeto. Rio de janeiro: Zahar, 2006. 